\title{
From interaction possibilities to real engagement: Paradoxes of media participation and the case of Banda Ampla, from the public Catalan television TV3
}

\author{
Fábio Ribeiro \\ Communication \& Society Research Centre (University of Minho), \\ University Trás-os-Montes e Alto Douro (UTAD)
}

DOI: 10.30547/worldofmedia.1.2019.4

\begin{abstract}
The concept of citizens' participation in everyday life has strong roots in the ancient Greek culture, commonly accepted as the birth of the occidental civilization. Especially from the 4th century BC to the 5th AD, assemblies and public opinion courts were part of this democratic ecosystem, where citizens could express their views on current topics. Inspired by the typical starting expression of such reunions - 'Who would like to talk?' (Sinclair, 1999) - this article tries to contribute to the general topic of public intervention in the media scope. In this sense, what kind of motivations led citizens to participate and interact with media institutions? What kind of troubling issues have been drawn by the scientific literature in this regard? Do real opportunities for participation differ from real audience participation? Thus, in an empirical framework, we analysed the overall social and mental representations of one sample of individuals who have participated in Banda Ampla, a public opinion programme broadcast in Barcelona, Spain. This article questioned participants about their personal motivations to participate as well as other generic thoughts on media and participation. Conclusions suggest an important paradox: participants somehow tend to neglect digital possibilities to interact with media, although the majority argue that it is essential for democracy that citizens have their say on current topics within society.
\end{abstract}

\section{Keywords}

Participation, citizens, public opinion, TV3, Catalonia, Banda Ampla.

Corresponding author:

Fábio Ribeiro, Communication \& Society Research Centre (University of Minho),

University Trás-os-Montes e Alto Douro (UTAD), Quinta de Prados, 5001-801 Vila Real, Portugal.

Email: fabior@utad.pt 


\section{Introduction}

It is widely reported that the birth of the occidental thought is profoundly rooted in the ancient Greek civilization, in a movement that had travelled first to Italy then to the rest of the European space. Especially important in the context of empowering citizens to engage with public affairs, Greek public forums and assemblies were fundamental to spread out the importance of democracy in the decision-making processes. In such amphitheatres, oval and/or round buildings with tiers of seats around a central open area, as those used in ancient Rome for gladiatorial contests, public matters were brought into discussion, widely participated by the Greek citizens, including a range of topics which included law and war, for instance (Sinclair, 1999).

It has also been acknowledged that since the Homeric period, around 4th century BC to the 5th AD, Greek Kings had legal determinations to promote such reunions with citizens, who had the opportunity to share personal thoughts and opinions towards the topics raised during the meetings. Nevertheless, the official recognition of a 'citizen', in this context, prevented women, slaves, children and foreigners from participating in the discussion.

Habermas famous suggestion of coffeehouses as spaces for interaction and participation is also often considered in the social realm of participation: 'This process offered the critical foundation for the expression and legitimacy of a truly democratic, and a truly reasonable, public opinion' (Cowan, 2004). These were indeed the practical idealization of the Habermasian landmark of public sphere, where activities of newspaper reading, political discussion could be decisive for engagement, awareness and participation.

Taking into account this historical inspiration, it is our ambition to draw some sort of comparison with some features of media in present times. For instance, this article assumes that public opinion programmes - or audience discussion programmes - may represent some of this democracy ideal. These spaces, often spread on radio and television, invited audiences to participate in the media, starting from an old classical telephone to more recent and advanced communication tools, digital and online ones.

\section{The ocean of definitions in the concept of 'participation'}

The dictionary ${ }^{2}$ identifies a very simple way to define 'participation': 'the fact of taking part, as in some action or attempt'. The verb 'to participate's is defined

\footnotetext{
${ }^{2}$ Dictionary.com. Available from: http://dictionary.reference.com/browse/participation

3 Dictionary.com. Available from: http://dictionary.reference.com/browse/ participate
} 
the following way: 'take or have a part or share, as with others; partake; share'. Although we might identify some ambiguity, we have to admit that there is an implication to a communicative performance, recognizing an active role posed to someone.

In addition, the context of 'participation' defines its nature. This is why Ernest Laclau and Chantal Mouffe (1985) stated that the concept of 'participation' has a 'floating signifying'. From politics to the media scope, citizens' engagement is probably an active behaviour, which conveys different aspects towards its nature. Recognising its centrality to our discussion, citizens' participation in the media has been claimed by a completely new post-electronic generation. Following Martins, such generation 'is developing human interaction, based on internet chats, electronic games, new social media, Second Life, Facebook and Twitter, for instance, which have shaken traditional and steady positions of family and community' (Martins, 2011). Academic research is still trying to acknowledge if such new possibilities of socialization represent an improved feature of social movements, with empirical consequences in communities and groups.

In the grasp of some theoretical contributions to this concept, Espen Yterberg defines citizens' participation in the media as 'a set of performance roles that are given by the production context and by the requirements of the format' (Yterberg, 2004). Gunn Sara Enli states that letting people participate in the media is positive for the democracy and the perception of its value: 'participatory formats are especially created to attract audiences and multiplatform formats are thus increasingly being embraced as one solution to the current challenges facing PSB associated with deregulation, digitalization and convergence' (Enli, 2008). Learning aspects are also brought in by Enli, as 'audiences were encouraged to climb the great ladder of culture, to move from darkness to enlightenment' (Enli, 2008).

Participation is hence seriously involved with a personal dimension of life. The subject is relevant for the emancipation towards participation. This is probably the reason why Kiwan includes the concept of 'motivation' as a decisive fragment for people to get involved in the media: 'understanding what motivates people to participate is crucial to developing an inclusive conception of citizenship' (Kiwan, 2007). Previous studies have pointed out possible outcomes of this motivation (Ribeiro, 2008) - expressing opinions, strong political background, spending time - but several studies highlight that only motivated citizens are able to participate in the media.

Evelina Dagnino considers that the concept of participation has most of its signifying nature outside the political scope. Instead, the media should fulfil the role of questioning public affairs such as social inequality and poverty, 
so that real intervention of people in these contexts of broadcasting could produce real changes in daily life. The Brazilian researcher also notes that citizens' participation in the media should be included in the field of moral, 'in the terms of solidarity, the great claim of this redefined participation, disconnected from its political and collective meaning, in order to establish firmly in the private territory confined to moral' (Dagnino, 2004).

Participation is not a concept free of criticism. Rosa Alfaro Moreno (2006) explains that most media institutions are keen to integrate citizens' voices in their domains as to only gather a faithful audience for commercial purposes. According to Moreno, this 'media marketing' deals with participation as a tool to ensure some certain level of audiences, making sure that this feeling of interaction is promoted all the time, creating a consistent image of such formats in audiences' routines with the media.

Besides motivation, technology embodies a definitive tool for the empowerment of participation itself. New digital and communicative landscapes, hand-by-hand fast, updated and live content, have been promoting the idea that participation is all around. Howard Rheingold (2008) once highlighted that text, audio and video alongside blogs, podcasts and video casts would be able to offer real chances for people to get involved in the media discourse. This possibility deals with countless studies that have been questioning people's abilities and perceptions on devices and participative formats, in the broad area of media literacy studies (EAVI, 2009; Pérez-Tornero, 2004).

\section{A conceptual framework:}

\section{'Participation' within media literacy studies}

As communication is strongly rooted with democracy it is obvious that some political institutions, such as the European Commission, make a particular call on citizens' participation towards the media. The US-based Center for Media Literacy claims that participation is an extension of citizenship and democracy. According to Thoman and Jolls, 'media literacy is one dimension of the typical education developed in this 21st century. It provides a structure of access, analysis, evaluation, content creation in different ways, from print sheets to video or Internet. Media literacy builds the comprehension of the media role in social terms, as well as other essential abilities to question and participate, perceived as key elements for democratic citizens' (Thoman \& Jolls, 2005).

In a semiotic point of view, media (re)build meanings and interfere in many of our social representations. However, it remains unclear why we should address a specific discipline of education towards the media scope. This has been the concern of many researchers. David Buckingham (2003) explained that media 
are large industries, generating employment and most of our information about the political process. Media institutions are the largest platforms for cultural expression through communication, by replacing family, church, school, as the strongest socialization agents in contemporary societies.

The concept of participation has been part of several media literacy studies. In the Study Assessment Criteria for Media Literacy Levels published in October 2009 by EAVI (European Association for Viewers' Interests), citizens' participation in the media is described as a social competence, a communicative skill, alongside content creation and social relations, in the top of the pyramid of Media Literacy Criteria Levels. Hence, the document assumes that media do develop a vital role in the promotion of the democratic values throughout Europe, namely by encouraging social cohesion, ethnic diversity and plural access. EAVI also points out that the importance of 'more spaces opened to the civil intervention in the decision making processes, which tend to create a healthier public life', is now clear to several international organisms, such as the European Commission, European Parliament and the Europe Council.

Jos Manuel Pérez Tornero (2004) also has an important study on this subject. In his paper about digital literacy, the Spanish researcher considers that this is a key concept in the information society, as an opportunity to address a new meaning of citizenship, based on responsibility and participation, in a cultural and humanist spirit. In this context, Pérez Tornero does not forget how important it is to consider motivation as a decisive step for people to interact more in the media. Raising critical consciousness, along with cultural and institutional innovation is one of the major tasks brought by participation, the author says.

\section{Observing live Banda Ampla Getting to know perceptions on participation}

Banda Ampla'5 was an audience discussion programme from public Catalonian television TV3, ended in 2012 for budgetary reasons. Since 2009, every Thursday night a group of citizens, selected by the producers, was invited to come live to the studio and talk about public and current matters of this Spanish region. According to the data provided by the media ${ }^{6}$, the programme was weekly

${ }^{4}$ This case study was part of the author's $\mathrm{PhD}$ research project, held temporarily in the Autonomous University Barcelona, in Spain, in the PUBLIRADIO research group, supervised by Professor Juan José Perona. In addition, Banda Ampla's uniqueness within the Spanish television scope played an important role in this study selection.

${ }^{5}$ Banda Ampla. Available from: http://www.tv3.cat/bandaampla

6 Ara.cat. Available from: https://www.ara.cat/media/TV3-prescindeixprograma-Banda-ampla_0_643735725.html 
followed by an average of 172.000 viewers. Hosted by Lidia Heredia (previously with Toni Cruanyes who had left the format), some invited specialists on the topic were also included to provide scientific or expertise approaches during the broadcasting.

In order to identify more precisely some of the most common aspects of Band Ampla, this research carried out a non-participation observation method into one of the broadcastings of the programme. On the 13th of January 2011, the programme was focused on then-called new legal framework of smoking in public spaces in Catalonia. This study highlights some of the technical procedures of the show and, in the second part, deals with a small survey over a sample of citizens who participated in that specific show.

Banda Ampla was held in the TV3 headquarters, Studio 1, in Sant Joan Despí, Barcelona. This large and modern studio was able to gather almost 100 participants, divided in three rows in two sides. In the centre of the set, the hostess Lídia Herédia was conducting the show with the main topic of discussion on a wide screen. This was a 1 h30 long programme (Figure 1).

Figure 1

\section{Banda Ampla studio overview}

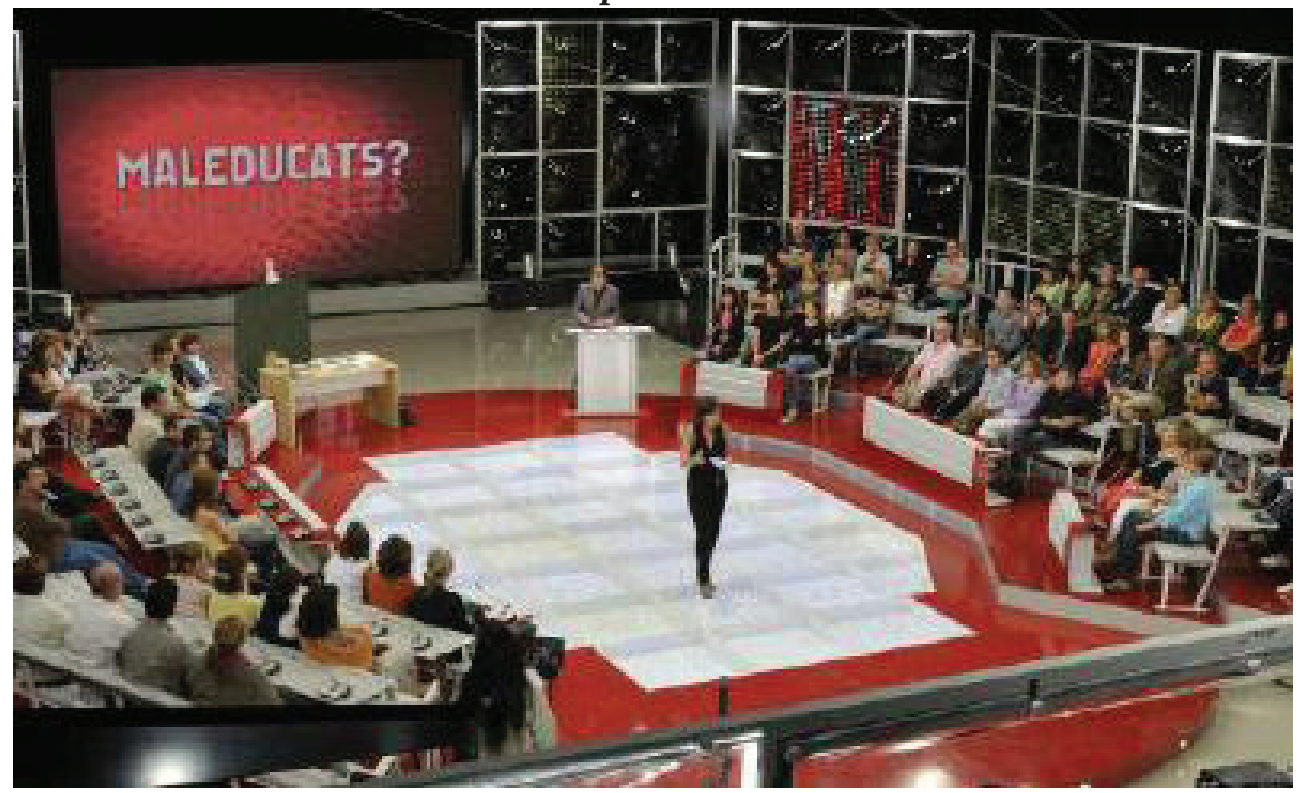

Source: http://magufos.crearimagen.com 
Participants could talk in Spanish, but Catalonian language was at the main core of the show. This was also a consequence of the selection of citizens to participate, as they lived in the vast region of Catalonia.

\section{Production details: Selecting participants and live on air}

This was a television format which broadcast for the Catalonian population, from Andorra, Catalonia, Valencia to the Balearic islands. According to the Government of Catalonia - Generalitat de la Catalunya ${ }^{7}-10$ million people live in this space. The problems that were arisen tended to discuss pertinent and upto-date topics of this area.

Following information provided by the Head of Producers, Trinidad Espejo, the overall participants were selected according to three ideas: 1) invited specialists on the subject (in this case study, the production invited some owners of bars, restaurants or even discos, who had to deal with smoke restrictions according to the already-mentioned new law); 2) contacting people who signed up for participation via e-mail or telephone; 3 ) contacts made by local Catalan associations in order to participate as well. This selection took almost a week beforehand.

Invited specialists came to the studio on their own, the rest of the participants did not. They usually arrived two hours before the beginning of the show, in one or two buses provided by the local organizations and/or the production. Welcomed by the staff, some snacks and light drinks were available to the group. Some young ladies were also in the room to help participants feel comfortable, providing assistance if requested. As time went on, one hour was left for Banda Ampla to be on air. Then, participants were requested to be in two lines to enter the studio. No telephones were allowed. No photos could be taken inside. Receptionists took a close look on the participants' behaviour, making sure that rules were followed including one key aspect. Citizens were asked to hand over a statement on their image rights, claiming that TV3 could use images of them to properly broadcast the programme, as well as for the post-production team, after the ending of the show.

\section{Minutes before on air: How the participation works live}

Right after collecting all the signatures, the participants started to sit down in their seats in studio, red and white coloured, following Banda Ampla's lettering

${ }^{7}$ Generalitat de Catalunya. Available from: http://www20.gencat.cat/portal/ site/Llengcat/menuitem.1d08009f459b71e7a129d410b0c0e1a0/?vgnextoid=ef4 0f9465ff61110VgnVCM1000000b0c1e0aRCRD\&vgnextchannel=ef40f9465ff61110 VgnVCM1000000b0c1e0aRCRD\&vgnextfmt=default 
and icon. Participants did not sit wherever they wanted, as the production told them where exactly to sit, probably as a way to ensure a good representation of the audience in the studio. So, there was a paper informing where to sit down. It was later explained that this practice was regarded in order to allow the hostess to know exactly where a specific participant would sit down and then interact live, knowing the name and the most important data to frame TV viewers about it, concerning to the debate development.

All sat in chairs, the Chief of the régie Eduard Calvó warned participants how to interact wisely during the show. Calvó addressed them all, ensuring that no one would misbehave according to the rules defined. He stressed out the concept of 'healthy participation', letting others talks, not interrupting active discussions, respecting time and the hostess instructions to talk. He noted that microphones were all over the seats, so getting the chance to talk on the topic would be perfectly possible for anyone. Calvó also presented the general guidelines of Banda Ampla and how it would be carried out in the two-hour long show: debates with specialists, participants' interventions, video interviews in bars and restaurants to be broadcast during the show as to enrich the debate on the topic. The producer emphasized the importance of language correctness of participation, avoiding slang or dirty words. Attacking others' views and opinions would not be allowed, the production stated.

After these recommendations Lídia Herédia walked down the studio. Participants applauded her as she waved and smiled. She was concerned about technical aspects, rehearsing with cameras and sound checking all suitable devices. Minutes before it all started, Herédia addressed the participants, reminding them some of the same aspects of 'good participation'. After this brief intervention, Lídia recorded the short video teaser of the then-upcoming programme, about sports and doping. The show was then all set to start.

\section{Understanding social representations about media participation}

As a complement research tool of the non-observation method mentioned above, a small questionnaire was handed over to a sample of participants before they joined the main studio of the show, in order to identify some critical opinions on several issues towards the intervention of citizens in the media, especially in this kind of public opinion formats. In this contact, from almost 90 participants, 51 have answered to the questions. This research tools intends to reveal early motivations and social constructions of participants in the process of engaging in the public opinion programme on television. 
Following Quivy and Campenhoudt, 'the questionnaire deals with an enquiry a group of individuals generally representative of a population, about their social, professional or familiar situation, as well as their opinions, attitudes regarding the options or human and social questions ${ }^{\text {'8 }}$ (Quivy \& Campenhoudt, 1992). This technique is no stranger to some disadvantages, as the authors warn about the potential harm of shallow answers, superficial and very little detailed ones: 'The results are often presented as simply descriptions, without dependent elements to fully understand the questions itself ${ }^{9}$. However, if a specific research question requires a certain number of answers, regardless of possible complex and long explanations, then the questionnaire is the most suitable technique, as stated in this article.

The focus of the questionnaire was to analyse social and mental representations of public opinion programmes. Hence, 13 questions intended to observe, for instance, what kind of evaluations are to be made about new communicative technologies, as respondents explained if they participated in other public opinion formats within the media. In addition, motivations to participate were also regarded, troubling issues and other questions on the importance of these programmes in the media.

\section{Results and analysis}

Questions were answered by 51 participants of this survey, 29 men and 22 women. When it comes to age, two categories emerge: from 16 to 47 years old (27 individuals); from 48 to 80 (24 participants).

In the first group of questions, generic aspects within the relationships between citizens and television were observed. 39 in 51 individuals watch television 'every day'. Regarding Banda Ampla, 5 participants said that they watched TV 'every week', as most of the respondents said that 'rarely' followed the show (20) and 5 had not known about the show until the moment they were invited to come to the studio and participate.

Measuring interaction with the show, 45 out of 51 respondents confirmed they had never participated in the show. Only two did it through e-mail and the show's official page on Facebook. Thus, it was not possible to study in depth the potentialities of participation outside the studio, evaluating their overall perceptions. Furthermore, dealing with the obstacles of participation, Charts 1 and 2 provide insights on participants' views about troubling issues which may prevent people to participate more in this programme:

${ }^{8}$ Author's translation based on the Portuguese edition of Quivy \& Campenhoudt (1992).

${ }^{9}$ Author's translation based on the Portuguese edition of Quivy \& Campenhoudt (1992). 


\section{WHY PEOPLE DO NOT PARTICIPATE?}

(ONE ANSWER PROVIDED)

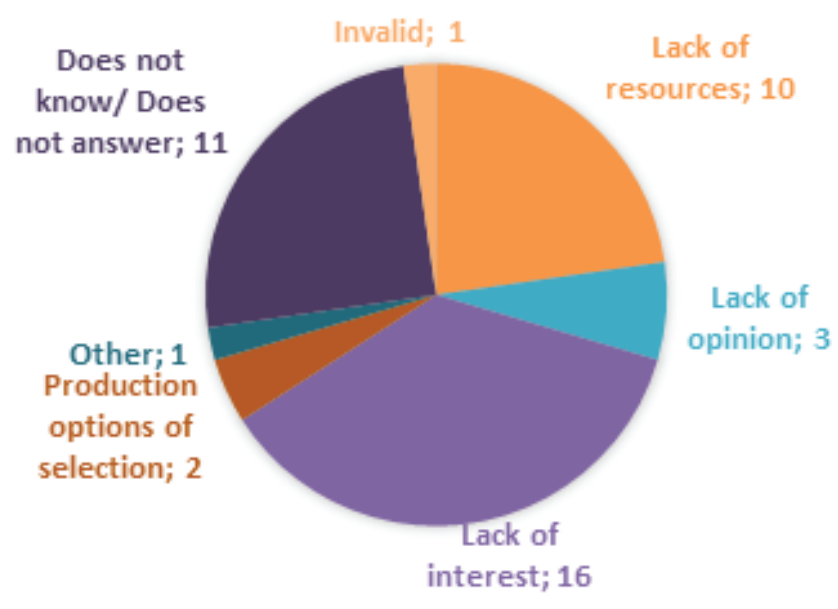

Chart 2

\section{WHY PEOPLE DO NOT PARTICIPATE?}

(TWO ANSWER PROVIDED)

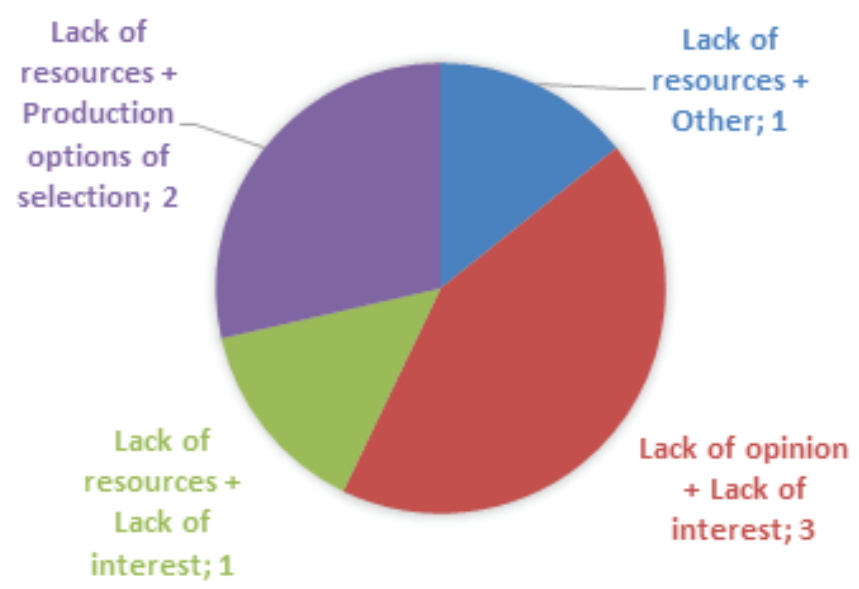


Following Charts 1 and 2, given that 12 participants did not answer this question, 32 of the overall sample chose one answer and 7 two possible explanations for the stated interrogation.

In the first group, results indicate the following: 10 answers mentioned the lack of technological resources; 3 referred the lack of citizens' interest, while two blamed the production selection of participants. As in the second group, results show: the pair 'lack of opinion' and 'lack of interest' was the most chosen one with 3 individuals, followed by 'lack of resources' and 'programme's selection of participants' with 2 answers. In a wider perspective, the explanation of 'lack of resources, such as technological ones' was the most selected one, with 17 responses, whilst 'lack of interest by the citizens' gathered 14 votes. These were the two greatest obstacles underlined by this sample of participants in Banda Ampla.

One of the critical aspects of the interaction between citizens and media deals with the definition of the motivations and constraints that lead people to media participation or prevented them from it. Following the previous question, respondents could answer providing one or two statements, as regarded in Chart 3:

Chart 3

\section{WHY DO YOU PARTICIPATE?}

(ONE ALTERNATIVE)






\section{WHY DO YOU PARTICIPATE?}

(TWO ALTERNATIVES)

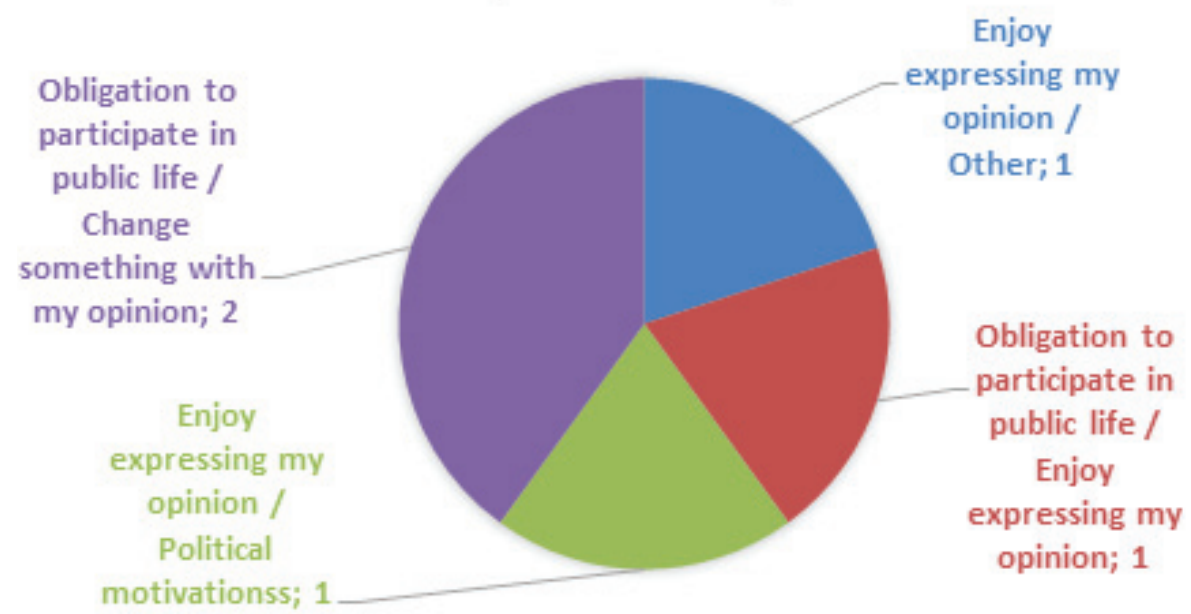

Considering that 11 participants did not answer, 35 of 40 respondents chose one alternative and the remaining 5 - two possibilities. In the first case of a single justification, 17 individuals recognised that their intervention is motivated by their joy to express their opinions in these programmes. Thus, 12 confirmed that it is part of our obligation as citizens to participate in public life, especially in the media. Far from these levels of popularity, 3 respondents feel that their participation can change something in social life, in other peoples' minds. In conclusion, 'joy to express opinions' (17) and 'obligation to participate in public life' (16) are the most alternatives combined.

The last part of the survey evaluated the relationship between participants and television. Hence, all respondents acknowledged that television should continue to promote this type of programmes. Justifying their views, 17 of them underlined the importance of citizens in the media productions, or as stated 'everyone has the right to give an opinion', 'citizens are the mirror of reality'. 4 of them did emphasize the public opinion programmes as active platforms for public to interact, 2 highlighted the active role of television in the social scope and 2 defended the rights to participate in public life or freedom of speech. Such an analysis was provided after a careful textual analysis.

In this research, few possibilities of crossing variables can be observed, as a great number of respondents confirmed that they had never participated in the programme before. This prevented further analysis to match results between 
those who participated from their homes and, consequently, developed their views of some participative technologies, for instance.

However, both men and women underlined the very same reasons to participate (joy of expression of their opinions and obligation as citizens to participate in public life). In the obstacles to a wider participation, there is also some balance, as both men (10) and women (6) are most concerned in the lack of interest by citizens to justify low levels of popular intervention in these programmes. It was also possible to analyse that the individuals who confirmed that they watch television every day - 39 out of 51 - pointed out the lack of interest and technological resources as main obstacles to a wider citizens' intervention. It states clear that watching television does not indicate per se, that these audiences feel motivated to participate.

\section{Final remarks}

It is also common sense to acknowledge that history tends to repeat itself. As it was stated in the first part of this study, Greek democratic societies revealed an important dimension in the access to participate in the public space. Women, slaves and foreigners were amongst those who could not attend public hearings promoted by the official representatives within the government. Moving the question of access a bit further, to the most recent context in the media ecology, access may be an important issue, but motivating citizens to participate has become critical for media institutions. The possibility to interact with media is real, happens on a daily basis, but motivating citizens to be part of such context of a public dialogue remains a very troubling issue, as many of them do not seem to be interested in engaging with digital tools, for instance, in public opinion programmes, as stated in the study. Hence, Habermas' widely studied coffeehouses seemed to have a possible comparison with these new media formats. The main differences lie in access and wide scope: coffeehouses were the place for intellectuals and elites to discuss current topics; public opinion programmes in television suggest an indiscriminate target and tend to reach wider audiences. However, both are defined by the same nature: discussing public affairs within citizens.

Banda Ampla was an important space to pose some questions regarding public participation in the media. It was considered that only a deep understanding of how these spaces work, may shed some light on doubts in this area.

However, it is clear now that this research only seeks to initiate part of a debate about plenty of possibilities to come. As Dahlgren (2006) stated, the disaffection between citizens and politics is a crucial debility in modern societies. Media may be a viable strategy to overcome this distance. Citizens' participation 
can find in the media plenty of possibilities of implementation, probably more direct than the ones provided by the traditional field of politics.

Although we may admit that some answers brought a few unravelling surprises, this was a contribution to share some of the social representations of a sample of citizens towards public participation in the media. Motivation to participate plays a decisive role. At the same time, the majority of respondents had not previously participated in the show, despite numerous technological opportunities for interaction. It is somehow obvious that only motivated citizens may participate in the media. Further research on this topic should analyse social and psychological motivations that may conduct or inhibit citizens to participate in the media, according to randomly defined in-deep interviews with citizens.

In the survey, some answers were curious, as well. Few, yet reliable, citizens explained that they had participated in Banda Ampla only as a way to learn more about a television set. Answers like these may indicate shallow perceptions on participations, but it is essential to understand that participation is more than that: it is about building a democratic society based on an interactive discussion. Key dimensions in our daily life deal with influence, knowledge and information. Also, if participation is designed to promote information, awareness and consciousness, one would expect that social influence could be triggered by these ways of people to have their say on public matters.

If information age is a reality, we do suggest that participation and social interaction play an active role in knowledge dissemination. However, the question of motivation, a permanent working task for media, shall also focus on those who do not participate, those who are still in social silence, in the shadow of participation.

\section{References}

BUCKINGHAM, D. (2003). Media education: Literacy, learning and contemporary culture. London, Polity Press.

CASTELLS, M. (2004). A gal xia Internet, reflex es sobre Internet, neg cios e sociedade. Lisbon, Gulbenkian.

COWAN, B. (2004). Mr. Spectator and the coffeehouse public sphere. Eighteenth-Century Studies, 37(3), pp. 345-366. Available from: http://www. jstor.org/stable/25098064

ENLI, G. (2008). Redefining public service broadcasting multi-platform participation. Convergence: The International Journal of Research into New Media Technologies, 14(1), pp. 105-120.

MARTINS, M. L. (2011). Crise no castelo da cultura. Das estrelas para os ecrãs. Coimbra, Gr cio Editor. 
PÉREZ TORNERO, J. (2004). A new model for promoting digital literacy. Digital Literacy. Available from: http://ec.europa.eu/education/archive/ elearning/doc/studies/dig_lit_en.pdf

RIBEIRO, F. (2008). A r dio e os ouvintes: a formula de uma rela o bipolar. Masters' thesis. Braga, University of Minho.

SINCLAIR, R. (1999). Democracia y participaci n en Atenas. Madrid, Alianza Editorial.

Study assessment criteria for media literacy levels (2009). Final report - EAVI for the European Commission. Brussels, October 2009. Available from: http:// ec.europa.eu/culture/media/literacy/docs/studies/eavi_study_assess_crit_ media_lit_levels_europe_finrep.pdf [Accessed 2nd June 2010].

YTERBERG, E. (2004). Formatting participation within broadcast media production. Media, Culture \& Society, 26(5), pp. 677-692. 